\title{
The ins and outs of lifelong learning
}

\author{
Stephen Roche ${ }^{1}$
}

Published online: 15 November 2016

(c) Springer Science+Business Media Dordrecht and UNESCO Institute for Lifelong Learning 2016

In 2013, the Editorial Board of this journal took the decision to bring its thematic scope and focus into closer alignment with the priorities of UNESCO. Thus, the International Review of Education gained a subtitle, Journal of Lifelong Learning. This was both a bold and a natural step; bold because there are risks attendant to changing an established brand, and natural because IRE has been at home within UNESCO since $1955 .{ }^{1}$ This decision was born of a desire that IRE should reflect a paradigm shift that has been taking place in education research and policy, one which has been explicitly promoted by our parent organisation. In the second IRE issue of 2013, in which the shift of focus was first announced (Roche 2013), I quoted the 1972 Faure Report, commissioned by UNESCO, which described lifelong education as "the master concept for educational policies in the years to come" (Faure et al. 1972, p. 182). The report envisaged the return of education "to its true nature, which is to be total and lifelong, and transcends the limits of institutions, programmes and methods imposed on it down the centuries" (ibid., p. 143). It would be "the principle on which the over-all organisation of a[n education] system is founded" (ibid., p. 143).

Lifelong learning might be compared to a wide-angle lens; it takes in aspects of learning that have always existed - such as adult, non-formal and informal learning - and offers conceptual space to the many new modes of learning which are emerging in the Information Age. It shifts the emphasis from questions of what and how (curriculum, method and mode of delivery) that have traditionally dominated

\footnotetext{
1 Founded in 1931 as the International Education Review, this journal was initially edited by Friedrich Schneider of the University of Cologne in cooperation with six institutes; three in Germany, two in the United States and one in Switzerland. For more on the history of the journal, see Dave (1984) and McIntosh (2002).
}

Stephen Roche

s.roche@unesco.org

1 UNESCO Institute for Lifelong Learning, Hamburg, Germany 
educational research, to questions of who and why (rights, access and societal impact). Lifelong learning goes hand in hand with the vision of a learning society, in which the common good of learning eclipses the increasingly marketised "good" of education. It recognises that successful human societies rely more on collaboration than on competition; that the young both support and are supported by their elders. Even more essentially, in the words of Jacques Delors, "[lifelong learning] is about knowing oneself better ... gaining a kind of self-esteem to help us deal with the risks and constraints of life, and acquiring the ability to take control of our own lives" (Delors 2013, p. 329).

The decision to shift the focus of IRE raised certain questions: what exactly do we understand by lifelong learning; what is included and what is excluded; what is the difference between a journal of comparative education and a journal of lifelong learning? I would venture to reply that the entire field of educational research is shifting towards an emphasis on lifelong learning, and therefore every journal of education is in the process of becoming a journal of lifelong learning. We have merely chosen to make this explicit. I say this because the idea that learning is a lifelong (not to mention life-wide) endeavour has by now taken deep root in educational policy and research, has been embraced by organisations as varied as the European Commission, UNESCO, the Organisation for Economic Co-operation and Development (OECD) and the World Bank. In fact, today, greater than the risk of its rejection is that of a false embrace, in which this idea is honoured more in rhetoric than action.

But, of course, editing is ultimately about putting certain things in and leaving others out, and thus the shift of focus was steered by a series of editorial decisions. Since 2013, I have favoured submissions that explore ways in which the idea of lifelong learning is reflected in education policy and practice. This has meant a preference for research in areas such as adult education, non-formal education, adult literacy, open and distance learning, vocational education and workplace learning, new access routes into formal education, and lifelong learning policies. These categories are not fixed and closed, but fluid and open. Moreover, I have tried to ensure that the transition has been as smooth as possible; that we attract new readers and authors without alienating or rejecting our existing ones.

I believe this current issue of IRE represents an arrival at the point we set out to reach in 2013. It illustrates the breadth and depth of the lifelong learning paradigm. It refers not only to the shift of emphasis from the educator to the learner, but also to that from childhood and youth to the entire lifespan, and from institutions to all loci of learning. Most importantly, it explores various ways in which learning can transform people's lives. It looks at specific interventions: village literacy centres in Kenya; prisons in Australia; hip-hop culture as a mode of learning. It also looks at the bigger picture: the ways that African formal education systems can respond to changes in the labour market; the wider benefits of adult literacy; the transfer of creative approaches to learning from non-formal to formal education; and the potential of higher education to aid the path of one developing country (Ethiopia) towards implementing the United Nations Sustainable Development Goals (SDGs).

The first article in this issue, entitled "Rethinking women's learning and empowerment in Kenya: Maasai village women take initiative", investigates the 
activities of a village-based literacy centre in Kenya and explores the benefits of community development activities on women's well-being. The author, Taeko Takayanagi, begins with an overview of adult literacy education and community development in Africa, giving particular attention to how literacy and informal learning assist in the empowerment of women. Next, she describes the organisation of a village-based literacy centre and, using narrative analysis, examines two Maasai women's experiences of literacy and community development activities. Through its engagement with literacy and informal learning in one community, this study also attempts to determine to what extent these female learners have been empowered through learning and community development activities. The author's conclusion is that grassroots literacy and informal learning have been effective in improving the quality of life for the village women, and should be encouraged and supported by external agencies.

There is a link between education and incarceration. Optimists may cite Victor Hugo's aphorism, "celui qui ouvre une porte d'école, ferme une prison" ["whoever opens a school, closes a prison"], yet the link between prison and school is more complex than that suggests. In the United States, which has the world's largest prison population, people speak of a "school-to-prison pipeline". Irrespective of which contention carries greater weight - that good schools prevent young people from slipping into crime, or poor ones lead them towards it - we can surely agree that once people find themselves behind bars, education and learning represent not only the best way they can spend their time, but also the most likely key to a better life post-release. Considering the extremely high costs of incarceration (comprising the actual cost of keeping someone locked up, the lost economic potential of an adult in their most productive years, and the "collateral damage" wrought on families and communities), one might expect that the argument for investment in prison education and learning would hardly need to be made. But prisoners differ from almost all other groups of adult learners in that their needs and well-being are explicitly subordinated to those of society, and in many cultures the desire for punishment of criminals is so strong that any consideration of prisoners' rights is politically contentious.

To get around this problem, those working in prison education often try to make a "failsafe" argument that educational measures are proven to reduce the rate at which prisoners, on release, re-offend. Yet, in considering which types of education and learning to support, the issue of punishment versus rehabilitation is never far from the surface. In their paper entitled "The role of art education in adult prisons: The Western Australian experience", Margaret Giles, Lisa Paris and Jacqui Whale set out to establish, on the basis of two large government datasets (records of 14,643 prisoners and ex-prisoners incarcerated in 2005-2010), whether art classes offered in prisons in the state of Western Australia contributed to a reduction in recidivism. In light of the difficulty of establishing a causal link based on the available data, they conclude with a plea not only for further research, but also for a less baldly utilitarian approach to prison learning. The ultimate value of art education in prison, they argue, may lie in the "transformational experience" it offers prisoners: a "reframing of self-identity" which is a necessary precursor to exiting the vicious cycle of crime and punishment. 
When the Faure Report was published in 1972, it referred to lifelong education rather than lifelong learning. While this report is still considered highly relevant as a philosophical template, the term lifelong learning is now preferred because it emphasises the agency of the learner rather than the intent of the educator. This distinction is not merely semantic; examples of the misuse of education as an instrument of colonialism and cultural hegemony are legion. One of the world's first comprehensive systems of free primary education was instituted in Ireland in 1831, with the intention of imposing the English language and English cultural norms in the British Empire's first, and in many ways most stubbornly resistant, colony (Akenson 2012). ${ }^{2}$ Only a naif would suggest that this aspect of education has been consigned to the past. To this day, it is scarcely possible for Africans to pursue formal education from primary to tertiary level through an indigenous African language $^{3}$ (UIL 2010). Not surprisingly then, the process of decolonisation involves un-learning imposed knowledge and rediscovery of the learner's own heritage. Since education systems more often than not perpetuate the colonial voice, even in countries which have achieved political independence, such un- and re-learning largely takes place at a non-formal level.

The third article of this issue, entitled "Contesting history and pursuing 'other' knowledge: A study of hip-hop and non-formal education among Native American youth in San Francisco and black Portuguese youth in Lisbon", questions the enduring colonial legacies experienced by Native American youth in the United States of America Portuguese youth of Cape Verdean origin in Portugal. The author, Miye Nadya Tom, examines how young people use hip-hop music to access knowledge which is denied to them in schools, give voice to their realities, and broadcast perspectives on race, place and belonging. When knowledge is negated in learning institutions, non-formal education created by youth becomes a powerful force in re-affirming tradition and enabling transformation through learning.

The number of young people entering the labour market in Africa will increase considerably over the next two decades. Africa has by far the youngest population of any continent, with nearly 200 million people aged 15-24, and this number is projected to double by 2045 . But perhaps even more significantly, the educational profile of Africa's youth is changing rapidly. Based on current trends, by 203059 per cent of 20-24-year-olds in sub-Saharan Africa will have received a secondary education, compared to 42 per cent currently (AfDB et al. 2012). Thus, the labour market will need to absorb not only a far greater number of people, but also a more educated and expectant workforce. This presents not only an economic challenge: studies have shown that, in fragile and conflict-affected areas, unemployment is a major reason why young men join militant groups. It is therefore imperative that African countries prepare for this impending change. An essential first step is to develop a process for assessing, analysing and anticipating labour market demand. Many countries struggle with a mismatch between labour market supply and

\footnotetext{
${ }^{2}$ It was not for another four decades that a similar provision was made for England (in the Elementary Education Act of 1870).

${ }^{3}$ Only 25 per cent of the languages used in secondary education and 5 per cent of the languages in higher education are indigenous to Africa (UIL 2010). Though perhaps it can be argued otherwise, I am not considering Afrikaans or Arabic as indigenous African languages.
} 
demand. In 2012 the Economist magazine reported that in South Africa, a country with an official unemployment rate of 25 per cent and 600,000 university graduates out of work, 800,000 posts remained vacant in the private sector alone (Economist 2012).

In his article entitled "Satisfaction des exigences minimales du marché du travail par le système éducatif: Evaluation dans un contexte de faible système d'information sur la formation et l'emploi" [Satisfying the minimum requirements of the labour market through the education system: Assessment in a context of weak training and employment data], author Calice Olivier Pieume presents a method to assess the minimum requirements of the labour market at specific periods, and to gauge the degree to which the education system satisfies these requirements. This allows governments and other education stakeholders to develop appropriate strategies to improve the quality of the offer. The method was developed especially for countries with weak systems of collecting data on education, training and employment, as is the case in most of sub-Saharan Africa.

The United Nations Sustainable Development Goals (SDGs) have brought literacy research back into an agenda aimed at understanding how literacy skills can effect positive change. Our fifth article, entitled "Adult literacy benefits? New opportunities for research into sustainable development" reviews progress in adult literacy, touches on existing perspectives on literacy, and illustrates four recent sources of information that can inform the revitalised agenda offered by the SDGs. The author, David Post, explores the value of new data from the Programme for the International Assessment of Adult Competencies (PIAAC) study conducted by the OECD, the World Values Survey (WVS), and the World Bank's Skills Toward Employment and Productivity (STEP) study for linking educational change to attitudinal and behavioural change. He also looks at emerging data on mobile learning. By integrating literacy into the SDGs, literacy researchers can reveal the channels through which literacy can contribute to social welfare and transformation.

Since the mid-1990s creativity has emerged as a dominant concept in educational policies, with many Western countries restructuring their education systems to promote critical and creative thinking. Despite the current emphasis on creativity in education policies worldwide, there is a shortage of models that capture the complexity of creativity and its infusion into formal school environments. Our sixth article, entitled "The development of a model of creative space and its potential for transfer from non-formal to formal education", proposes that the promotion of creativity in education is best achieved by taking a systematic and multifaceted approach. The authors, Irene White and Francesca Lorenzi, present a multidimensional model, derived from non-formal education, for the promotion of creativity in schools. They developed this model based on data gathered in a study of a selffunded, independent arts organisation in Ireland that provides free mentoring in creative writing, particularly to young people and disadvantaged youth. Their model encompasses three distinct yet interrelated dimensions of a creative space physical, social-emotional and critical. They argue that the provision of creative space in schools represents a small but significant step towards the promotion of creativity in education, and conclude with a call for further research that may "result 
in more specific guidelines for educators and educational managers to favour the infusion of creativity into schools".

In recent years, the government of Ethiopia has embarked on an ambitious agriculture development strategy aimed at raising Ethiopia to the status of a middleincome-level country by 2025 . Encouraged by the international development push behind the United Nations Sustainable Development Goals (SDGs), the rapid expansion of public universities has taken centre stage in equipping a new generation with the expertise needed to fuel the country's economic development. While impressive strides have been made over the last two decades, various development challenges threaten to derail this promising progress. Our final article of this issue, entitled "The role of Ethiopia's public universities in achieving the United Nations Sustainable Development Goals" examines three of the main challenges - urbanisation, climate change and food security - and the potential for universities to address them. Based on a study using key informant analysis research with 50 experts in Ethiopian education and development, the author, Paul O'Keeffe, concludes that the developing public university system offers promising capabilities to assist the country on its developmental path despite many inherent problems.

\section{References}

AfDB (African Development Bank), OECD (Organisation for Economic Co-operation and Development), UNDP (United Nations Development Programme) \& UNECA (United Nations Economic Commission for Africa) (2012). African economic outlook 2012: Promoting youth employment in Africa. Retrieved 19 October 2016 from https://www.Users/mac/Downloads/AEO2012_EN.pdf.

Akenson, D. H. (2012). The Irish education experiment: The national system of education in the nineteenth century (Vol. 1). Abingdon: Routledge.

Dave, R. H. (1984). Introduction to the thirtieth volume of the IRE. International Review of Education, $30(1), 1-9$.

Delors, J. (2013). The treasure within: Learning to know, learning to do, learning to live together and learning to be. What is the value of that treasure 15 years after its publication? International Review of Education, 59(3), 319-330.

Economist. (2012, 21 January). Education in South Africa. Still dysfunctional. Standards still leave a lot to be desired. The Economist. Retrieved 19 October 2016 from http://www.economist.com/node/ 21543214.

Faure, E., et al. (1972). Learning to be. The world of education today and tomorrow. Paris/London: UNESCO/Harrap.

McIntosh, C. (2002). Editorial introduction international review of education: A journal of many incarnations. International Review of Education, 48(1/2), 1-20.

Roche, S. (2013). Plus ça change: Change and continuity at the international review of education. International Review of Education, 59(2), 153-156.

UIL (UNESCO Institute for Lifelong Learning). (2010). Why and how Africa should invest in African languages and multilingual education. An evidence- and practice-based policy advocacy brief. Hamburg: UIL. 